\title{
PRÁTICAS DE EXTENSÃO UNIVERSITÁRIA: FORMAÇÃO DE EXTENSIONISTAS E A INTEGRAÇÃO COM A SOCIEDADE DOI: $d x$. doi.org/10.18616/inser08
}

Joelcy José Sá Lanzarini ${ }^{1}$

Daniel Ribeiro Preve ${ }^{2}$

Milla Lúcia Ferreira Guimarães ${ }^{3}$

Marina Constante Pereira ${ }^{4}$

Júlia Constante Pereira ${ }^{5}$

Gabriel Preuss ${ }^{6}$

\section{INTRODUÇÃO}

A legislação preconiza a indissociabilidade entre pesquisa-ensino-extensão no sistema de educação superior brasileiro. Historicamente, as universidades têm desenvolvido de forma satisfatória a pesquisa e o ensino, enquanto a extensão tem sido aplicada meramente para atender às exigências legais.

Recentemente, a legislação voltou a centrar o foco na curricularização da extensão até o ano de 2024 , em que $10 \%$ da carga horária das

${ }^{1}$ Mestre em Desenvolvimento Socioeconômico.

${ }^{2}$ Doutorando em Direito. Professor na UNESC. Vice-Reitor da UNESC. E-mail: drp@unesc.net ${ }^{3}$ Mestre em Educação. Professora na UNESC.E-mail: mfg@unesc.net

${ }^{4}$ Graduada em Ciências Biológicas (UNESC). E-mail: mariinaconstante@hotmail.com ${ }^{5}$ Acadêmica do curso de Ciências Contábeis da UNESC.E-mail: julia_constantep@hotmail.com ${ }^{6}$ Graduado em Ciências Biológicas (UNESC).E-mail: gabriel_preuss@hotmail.com 
disciplinas devem estar alocadas com atividades de extensão. Isso se tornou um desafio para a maioria das universidades brasileiras, uma vez que essas atividades não fazem parte de seu cotidiano.

Ao buscar atender a essas regulamentações, a UNESC tem destinado, desde 2004, um percentual dos seus esforços e de seu orçamento para editais internos de extensão, selecionando projetos que visem a difundir os conhecimentos gerados pelo seu corpo docente. Para que os projetos tenham a eficácia desejada, é necessário formar um grupo de extensionistas em programas contínuos de capacitação em extensão ou em programas pontuais específicos de formação continuada.

O presente capítulo discorrerá, em sua parte inicial, sobre a contextualização histórica da extensão enquanto componente da formação de nível superior sobre as ações desenvolvidas pela Pró-Reitoria de PósGraduação, Pesquisa e Extensão juntamente com os Fóruns Internos de Extensão, buscando levantar as demandas da sociedade de tal forma que possam ser elaborados projetos de extensão que visem a atender a essas demandas. Por fim, tratar-se-á das ações desenvolvidas pelos programas e projetos de extensão dentro da Unidade Acadêmica das Ciências Sociais Aplicadas (UNACSA).

\section{CONTEXTUALIZAÇÃO HISTÓRICA DA EXTENSÃO}

A trajetória de implantação da extensão universitária no sistema de ensino superior no Brasil é recente. As primeiras experiências ocorreram em 1911, na USP, em São Paulo, e em 1920, em Viçosa (MG), na Escola Superior de Agricultura e Pecuária, por meio de cursos e conferências. Após 1964, com a instalação da ditadura militar no País, inicia-se um processo de alterações no sistema educacional de nível superior. 
Em 1968, foi aprovada a Lei Básica da Reforma Universitária, Lei $\mathrm{n}^{\circ}$ 5.540/68 (BRASIL, 1968), definindo que as universidades e as instituições de ensino superior deveriam levar à comunidade, sob a forma de cursos e serviços especiais, as atividades de ensino e os resultados da pesquisa que lhe são inerentes, ficando, assim, instituída a Extensão Universitária (NOGUEIRA, 2005).

Outras legislações surgiram. Conforme Lima (2014, p. 3):

[...] além do artigo 207 da Constituição Brasileira de 1988, a extensão universitária está também contemplada na Lei de Diretrizes e Bases da Educação Nacional - LDB (Lei no 9.394), de 1996, por meio do artigo 46 [...].

Nesse contexto,

Embora haja evidência dos avanços significativos acerca do reconhecimento da extensão, enquanto dimensão acadêmica, é preciso refletir como qualificar essas ações, já que o conhecimento científico se dá por meio de uma grande diversidade de áreas, fazendo com que o nível de complexidade acerca das ações extensionistas se torne ainda maior. (LIMA, 2014, p. 3).

Como conceito de Extensão Universitária, adota-se este, definido pelo Fórum de Pró-Reitores das Instituições Públicas de Educação Superior Brasileiras - FORPROEX (1987, p. 11):

A extensão universitária é o processo educativo, cultural e científico que articula o ensino e a pesquisa de forma indissociável e viabiliza a relação transformadora entre universidade e socie- 
dade. A extensão é uma via de mão-dupla, com trânsito assegurado à comunidade acadêmica, que encontrará, na sociedade, a oportunidade de elaboração da práxis de um conhecimento acadêmico. No retorno à universidade, docentes e discentes trarão um aprendizado que, submetido à reflexão teórica, será acrescido àquele conhecimento. Esse fluxo, que estabelece a troca de saberes sistematizados, acadêmico e popular, terá como consequências a produção do conhecimento resultante do confronto com a realidade brasileira e regional, a democratização do conhecimento acadêmico e a participação efetiva da comunidade na atuação da universidade. Além de instrumentalizadora deste processo dialético de teoria/prática, a extensão é um trabalho interdisciplinar que favorece a visão integrada do social.

A extensão universitária é um processo de transferência do conhecimento para a sociedade. É, portanto, um processo de educação. Freire (1974) diz que, se a educação sozinha não transforma a sociedade, sem ela, tampouco, a sociedade muda.

Independentemente do conceito atribuído ou da abrangência dos objetivos pretendidos, a Extensão Universitária caracteriza-se, indiscutivelmente, como um espaço propício para aprendizagem e desenvolvimento de competências de discentes e de docentes. (PREVE; SOUZA; GUIMARÃES, 2015, p. 10).

Além disso, a extensão pode ser compreendida como um “[...] estímulo para a reflexão e a crítica [...]", provocando no aluno a necessidade de levar "[...] a informação para um espaço menos prioritário [...]", favorecendo, assim, "[...] o desenvolvimento da formação humana e da transformação social." (SANTOS, 2012, p. 15). 
Mantenedora da primeira escola de nível superior criada no sul de Santa Catarina, a Fucri emergiu de um movimento comunitário regional que culminou com a realização de um seminário de estudos pró-implantação do ensino superior no sul catarinense. $\mathrm{O}$ evento contou com a participação de educadores, intelectuais, políticos, magistrados, lideranças comunitárias da sociedade civil organizada e imprensa.

A Fucri foi criada pela Lei $n^{\circ}$ 697, de 22 de junho de 1968, com cursos voltados para o magistério. Com o crescimento do sul do Estado, foram criados outros, visando à satisfação da demanda empresarial. Assim, a instituição sofreu alteração estatutária em 1973 e, em 1988, foi reconhecida como utilidade pública pelo Decreto Federal no $72.454 / 73$, pelo Decreto Estadual no 4.336/69 e pelo Decreto Municipal no 723/69. A Fucri iniciou suas atividades nas dependências do Colégio Madre Tereza Michel, com o curso pré-vestibular. Em 1971, passou a funcionar na Escola Técnica General Oswaldo Pinto da Veiga (SATC) e, em junho de 1974, mudou-se para o atual Campus Universitário, no Bairro Universitário, em Criciúma.

Até setembro de 1991, a Fucri mantinha quatro unidades de ensino: A Faciecri, a Esede, a Estec e a Escca. Com o desencadeamento do processo de universidade, algumas ações foram executadas. Entre elas, a unificação regimental e a criação da Unifacri (União das Faculdades de Criciúma), resultante da integração das quatro escolas.

Em 24 de setembro de 1991, o Conselho Estadual de Educação, pelo parecer no 256/91, aprovou o regimento unificado da Unifacri, cujo processo de transformação em Unesc foi encaminhado ao Conselho Federal de Educação em 1991, sendo aprovado em agosto de 1992 pelo parecer no 435/92 do CFE. Em 1993, em face a transferência para o Conselho Estadual de Educação da competência de criação de universidades, o projeto da Unesc foi encaminhado ao CEE, que, em fevereiro de 1993, constituiu a Comissão de Acompanhamento, cuja atribuição era acompanhar o processo de transformação da Unifacri em Unesc. 
Em 3 de junho de 1997, o Conselho Estadual da Educação aprovou, por unanimidade, o parecer do Conselheiro Relator e, em sessão plenária, em 17 de junho de 1997, também por unanimidade, aprovou definitivamente a transformação em Universidade do Extremo Sul Catarinense (Unesc), que definiu como missão "Promover o desenvolvimento regional para melhorar a qualidade do ambiente de vida", tendo a Fucri como sua mantenedora.

Já em 11 de agosto de 1997, a Universidade recebeu sua homologação, que equivale à "certidão de nascimento", assinada pelo secretário de Educação, João Mattos, com a presença do vice-governador, José Augusto Hülse. Em 18 de novembro, ocorreu a instalação oficial da Unesc no Teatro Elias Angeloni, com a participação de autoridades, empresários, professores, alunos e funcionários da instituição.

A Universidade do Extremo Sul Catarinense (Unesc) é uma universidade comunitária que tem como missão educar, por meio do ensino, pesquisa extensão, para promover a qualidade e a sustentabilidade do ambiente de vida, estabelecendo uma relação interativa com a comunidade. Por meio do envolvimento de professores e estudantes, a Universidade desenvolve, atualmente, diversos programas, projetos e ações de extensão.

A extensão na Unesc é assumida como dimensão que proporciona aos docentes e aos discentes o contato com a realidade social, favorecendo a retroalimentação do ensino e da pesquisa. Pode ser entendida como serviços que a Universidade presta à sociedade, gerando alternativas de ação para que atendam às expectativas e às problemáticas da população. Pode ser ainda um espaço fértil para o exercício e a conquista da emancipação crítica, tanto da comunidade acadêmica quanto da sociedade (UNESC, 2015).

A relevância social da extensão na Unesc é concebida em três eixos norteadores:

a. a formação humana e técnica da comunidade acadêmica, na esteira do princípio da indissociabilidade com o ensino e a pesquisa; 
b. o compromisso com o empoderamento comunitário e com o desenvolvimento econômico, humano e social, em especial da área de atuação da instituição;

c. primar pela ação básica nos princípios de sustentabilidade, ancorada no tripé econômico, social e ambiental, em especial da área de atuação da instituição.

A extensão é o meio que possibilita a inserção social, constituindo-se fator de integração entre o ensino e a pesquisa, garantindo o intercâmbio de conhecimento entre a universidade e a sociedade.

Segundo Santos (2012, p. 11), “[...] o papel primordial da universidade é de gerar e difundir conhecimentos e saberes". Entende-se que produzir conhecimento, interagir com a sociedade, inovar tecnologias, difundir a ciência e a cultura e trocar conhecimentos com as diversas áreas envolvidas são objetivos da extensão universitária, que, portanto, devem ser alcançados em qualquer projeto de extensão.

A Pró-Reitoria de Pós-Graduação, Pesquisa e Extensão, no ano de 2013, realizou diversos fóruns de avaliação, mobilização e proposição das atividades extensionistas na instituição. Participaram do processo mais de 400 docentes e discentes em debates, nas Unidades Acadêmicas e Institucionais, as quais permitiram a reflexão para o planejamento das ações de extensão na Unesc para os próximos 10 anos.

Dentre tantas demandas emanadas nos Fóruns, convém destacar a criação do "Programa Extensão Território Paulo Freire", da ação "Você na Unesc" e da "Formação Permanente em Extensão", além da criação da coleção de e-books "Práticas e Saberes em Extensão".

No que diz respeito ao "Programa de Extensão Território Paulo Freire", cabe salientar que, embora a iniciativa tenha partido da Unesc, ele foi construído juntamente com as lideranças comunitárias da região da Grande Santa Luzia e com a União de Associações de Bairros de Criciúma (UABC), levando em consideração as demandas da população daquela re- 
gião. A funcionalidade do programa consistiu na aprovação de 17 projetos na área ambiental, de saúde, de educação, de sociais aplicadas, de cidadania, de engenharias e de tecnologias, em mais de 12 bairros da Grande Santa Luzia, região situada no entorno da instituição, localizada no município de Criciúma, SC.

A ação "Você na Unesc" consiste na integração das comunidades dentro do ambiente da universidade, com o objetivo de oportunizar às lideranças comunitárias o conhecimento de algumas das atividades desenvolvidas no campus da UNESC, visando à democratização e ao acesso das mesmas.

\section{UNACSA E OS PROGRAMAS E PROJETOS DE EXTENSÃO}

A Unidade Acadêmica de Ciências Sociais Aplicadas (UNACSA) da Unesc constitui a instância básica da universidade que congrega docentes, discentes e funcionários técnico-administrativos para a atuação integrada nas dimensões do ensino, da pesquisa e da extensão, no âmbito das áreas de conhecimento e dos campos de formação acadêmico-profissionais das Ciências Sociais Aplicadas.

A UNACSA é composta por Colegiado, Diretoria e Coordenações de Ensino de Graduação, Pesquisa e Pós-Graduação e Extensão. Nela estão inseridos os cursos de graduação em Administração de Empresas, Administração e Comércio Exterior, Ciências Contábeis, Direito, Ciências Econômicas, Secretariado Executivo e Tecnólogos em Gestão, todos na modalidade presencial, bem como Gestão Comercial, Gestão Financeira, Gestão de Marketing e Gestão de Recursos Humanos. Na modalidade a distância, a Unidade oferta o curso de graduação em Tecnologia em Gestão Comercial. Possui também um programa de Pós-Graduação Stricto Sensu (Mestrado) em Desenvolvimento Socioeconômico aprovado pela Capes. 
Na UNACSA, a extensão é realizada a partir de um eixo central, denominado Programa de Extensão, o qual congrega um conjunto de projetos e outras ações de extensão (cursos, eventos, ação comunitária e prestação de serviços), que, preferencialmente, integram as atividades de extensão, de pesquisa e de ensino.

Um dos pressupostos perseguidos pela UNACSA é a integração entre programas, entre projetos e entre programas e projetos. A interdisciplinaridade é percebida na forma como interagem, entre si, programas e projetos. No processo de elaboração das ações dos programas e/ou projetos, busca-se a participação de profissionais das mais diversas áreas do conhecimento, muitas vezes contando com a participação de professores e acadêmicos de outras unidades acadêmicas.

Os programas de extensão devem promover a articulação dos diferentes setores da universidade e dos seus diversos atores (professores, acadêmicos e comunidade), além de ter caráter orgânico-institucional, clareza de diretrizes, orientação para um objetivo comum e propostas de ações a médio e longo prazo. Em consonância com a missão institucional, são organizados, a partir de áreas temáticas, áreas de conhecimento e linhas de extensão, devendo congregar as várias atividades ao redor de um eixo (temática) comum.

A UNACSA, em 2015, possuía três Programas de Extensão, a saber:

\section{PAES (PROGRAMA DE AÇÕES EM ECONOMIA SOLIDÁRIA)}

Esse programa se assenta em um conjunto de ações de caráter orgânico-institucional, de médio a longo prazo, com diretrizes orientadas à construção de um programa de estudos e ações que estimulem a inclusão produtiva de jovens e adultos, com ênfase em pressupostos de economia solidária e princípios de autogestão, articulando-se com projetos e ações 
de extensão universitária, aprovados bianualmente por meio de edital de seleção de projetos.

Ao longo dos sete anos de existência, o PAES coordenou mais de 10 projetos de extensão. Todos os projetos aprovados tiveram um viés inclusivo, os quais buscaram auxiliar iniciativas de produção, a fim de que se transformassem em oportunidade de geração de emprego e renda para as famílias, além da reinserção social.

Os projetos de extensão são escritos por professores do quadro regular da universidade, que preveem o desenvolvimento de ações direcionadas para alcançar os objetivos propostos. Cada projeto aprovado é contemplado com dois acadêmicos bolsistas, os quais ficam responsáveis pela execução do projeto.

Como resultado dos projetos desenvolvidos, foi coordenado o processo de formação de uma cooperativa de agricultores familiares dos municípios de Armazém, Gravatal, São Bonifácio, São Martinho e Tubarão, com mais de 100 associados, a COOPERRICA. A implantação da Feira de Economia Solidária na Unesc, no ano de 2011, permitiu a participação de agricultores familiares e de produtores de artesanato para obtenção de trabalho e de renda. Atualmente, está auxiliando um grupo de mulheres dos clubes de mães da cidade de Criciúma a formar uma cooperativa de artesãs, a fim de permitir que alcancem o mercado, gerando emprego e renda. Também está participando como apoiador da implantação de um sistema de certificação comunitária para produtos orgânicos de agricultores da região da AMREC, beneficiando cerca de 30 produtores.

O PAES ainda coordena o Fórum Regional de Economia Solidária, o qual é uma instância de governança da economia solidária da região. Esse fórum tem poder deliberativo nas questões ligadas à economia solidária regional, representando a região da AMREC no Fórum Estadual e Nacional de Economia Solidária. 


\section{PEDIC (PROGRAMA DE EXTENSÃO EM DIREITO E CIDADANIA)}

Direito e Cidadania para Todos é um programa de extensão que discute a cidadania e o acesso a direitos fundamentais e demais questões ou temáticas consagrados na legislação, cuja efetivação é necessária para a emancipação dos indivíduos e da comunidade.

Ele propõe a socialização de informações e a discussão com o público-alvo de temáticas relativas ao direito da criança e do adolescente, ao direito do consumidor, ao direito do trabalho e previdenciário, ao direito do idoso, ao direito da família e da violência doméstica e familiar, às questões de gênero, à assistência judiciária aos reeducandos dos estabelecimentos penais, bem como ao encaminhamento das demandas individuais e coletivas identificadas a entidades aptas a solucioná-las.

Tem por objetivo estabelecer, por meio de debates públicos e socialização de informações, a integração entre a universidade (docentes e discentes) e a comunidade externa, fomentando, além da criação de espaços públicos que garantam o exercício da cidadania, ações individuais e coletivas que busquem a efetivação de direitos fundamentais.

\section{POPE (PROGRAMA DE ORIENTAÇÃO AO PEQUENO EMPREENDEDOR)}

O Programa de Orientação ao Pequeno Empreendedor, inicialmente, objetivava realizar visitas orientadas aos empreendedores, a fim de prestar assistência técnica e de capacitar os tomadores de microcrédito. Destaca-se que o fornecimento de orientação aos microempreendedores, tomadores de microcrédito voltado à produção, supre uma lacuna ex post à concessão do crédito para uma parcela da população que não tem acesso aos recursos disponibilizados pelo sistema financeiro tradicional, sobretudo para um segmento da população vulnerável socialmente. Nesse sentido, 
a assistência e a orientação democratizam o acesso ao crédito e ajudam o microempreendedor a resistir às vicissitudes do mercado, criando maiores perspectivas de crescimento e de prosperidade.

O POPE é um programa multidisciplinar, visto que estão inseridos em suas atividades acadêmicos e professores dos cursos de Administração, Ciências Econômicas, Ciências Contábeis, Secretariado Executivo, Tecnologia em Gestão e Direito. Todos os docentes e discentes trabalham de forma articulada, com vistas a atender às demandas das comunidades assistidas pelas ações de extensão.

Diante da necessidade de atender a novas demandas, além dos tomadores de crédito do Credisol, o POPE começou a expandir suas ações no sentido de atender a outros públicos, de forma paralela, oferecendo a capacitação empreendedora e a assistência na gestão dos microempreendimentos, por intermédio de projetos de extensão universitária.

Os projetos vinculados aos programas têm propostas de atuação na realidade social, de natureza acadêmica, e cumprem o preceito da indissociabilidade entre ensino-pesquisa-extensão, compreendendo ações processuais e contínuas de caráter educativo, social, cultural, científico e tecnológico, com objetivo específico e prazo determinado. São ações que possibilitam a formação de um elo entre a universidade e a sociedade.

\section{FORMAÇÃO PERMANENTE EM EXTENSÃO}

A Formação Permanente em Extensão da Unesc tem o propósito de instrumentalizar professores, sobretudo os recém-contratados, e estudantes sobre os processos de extensão na universidade. São momentos de uma riqueza ímpar, pois, em um mesmo ambiente, reúnem-se professores e acadêmicos, experientes ou novatos, debatendo as experiências individuais ou coletivas dos extensionistas. A partir de 2014, como resultado das de- 
mandas apuradas nos fóruns de extensão realizados pela PROPEX, iniciaram-se os cursos de formação básica em extensão, os quais são realizados em etapas. Inicialmente, divide-se o público em professores e acadêmicos, a fim de fazer um aprofundamento teórico sobre o assunto, como forma de instrumentalizar cada um dos segmentos, de acordo com as suas especificidades. No ano de 2014, foram realizadas várias etapas de formação em extensão, as quais são demonstradas no Quadro 1:

Quadro 1 - Formação em extensão realizada em 2014

\begin{tabular}{|c|l|l|}
\hline Módulo & \multicolumn{1}{|c|}{ Tema abordado } & \multicolumn{1}{|c|}{ Público } \\
\hline I & Extensão universitária: concepções e práticas & $\begin{array}{l}\text { Professores e acadêmicos } \\
\text { bolsistas }\end{array}$ \\
\hline II & $\begin{array}{l}\text { Fórum de políticas e programas institucionais de extensão } \\
\text { da Unesc (Parte 1) }\end{array}$ & $\begin{array}{l}\text { Professores e acadêmicos } \\
\text { bolsistas }\end{array}$ \\
\hline III & $\begin{array}{l}\text { Fórum de políticas e programas institucionais de extensão } \\
\text { da Unesc (Parte 2) }\end{array}$ & $\begin{array}{l}\text { Professores e acadêmicos } \\
\text { bolsistas }\end{array}$ \\
\hline IV & $\begin{array}{l}\text { Estratégias de comunicação para abordagens de extensão } \\
\text { na comunidade }\end{array}$ & $\begin{array}{l}\text { Professores e acadêmicos } \\
\text { bolsistas }\end{array}$ \\
\hline V & $\begin{array}{l}\text { Elaboração de projetos de extensão universitária (editais } \\
\text { internos) }\end{array}$ & $\begin{array}{l}\text { Professores e acadêmicos } \\
\text { bolsistas }\end{array}$ \\
\hline VII & $\begin{array}{l}\text { Elaboração de projetos de extensão (editais externos, } \\
\text { como: Proext, Rondon e outros) }\end{array}$ & $\begin{array}{l}\text { Professores e acadêmicos } \\
\text { bolsistas }\end{array}$ \\
\hline
\end{tabular}

Fonte: Dados da Pesquisa (2015).

A programação para o ano de 2015 foi extensa. O Quadro 2 apresenta as atividades realizadas: 
Quadro 2 - Formação em extensão realizada em 2015

\begin{tabular}{|c|c|c|}
\hline Módulo & Tema abordado & Público \\
\hline I & Como posso fazer extensão na Unesc? & $\begin{array}{l}\text { Professores recém-contratados } \\
\text { pela universidade }\end{array}$ \\
\hline II & Como posso fazer extensão na Unesc? & $\begin{array}{l}\text { Acadêmicos } \\
\text { extensionistas }\end{array}$ \\
\hline III & $\begin{array}{l}\text { Elaboração de projetos de extensão universitária } \\
\text { (editais externos) }\end{array}$ & Professores em geral \\
\hline IV & Aplicação da filantropia em projetos de extensão & $\begin{array}{l}\text { Coordenadores de extensão e } \\
\text { programas de extensão }\end{array}$ \\
\hline $\mathrm{V}$ & $\begin{array}{l}\text { Refletindo as experiências atuais dos projetos de } \\
\text { extensão - UNACSA }\end{array}$ & $\begin{array}{l}\text { Professores extensionistas } \\
\text { dos atuais projetos de } \\
\text { extensão da UNACSA }\end{array}$ \\
\hline VI & $\begin{array}{l}\text { Refletindo as experiências atuais dos projetos de } \\
\text { extensão - UNACSA }\end{array}$ & $\begin{array}{l}\text { Acadêmicos extensionistas } \\
\text { dos atuais projetos de } \\
\text { extensão da UNACSA }\end{array}$ \\
\hline VII & $\begin{array}{l}\text { Como transformar experiências e ações de extensão } \\
\text { em publicações acadêmicas? }\end{array}$ & $\begin{array}{l}\text { Professores e alunos em } \\
\text { geral }\end{array}$ \\
\hline VIII & Políticas públicas e extensão universitária & $\begin{array}{l}\text { Professores e alunos em } \\
\text { geral }\end{array}$ \\
\hline IX & $\begin{array}{l}\text { Elaboração de projetos de extensão universitária } \\
\text { (editais internos) }\end{array}$ & Professores em geral \\
\hline $\bar{X}$ & Estratégias para avaliar a extensão universitária & $\begin{array}{l}\text { Coordenadores de extensão e } \\
\text { programas de extensão }\end{array}$ \\
\hline XI & Como posso fazer extensão na Unesc? & $\begin{array}{l}\text { Professores recém- } \\
\text { contratados na Unesc }\end{array}$ \\
\hline XII & Como posso fazer extensão na Unesc? & $\begin{array}{l}\text { Acadêmicos } \\
\text { extensionistas }\end{array}$ \\
\hline $\mathrm{XIII}$ & Direitos Humanos e extensão universitária & $\begin{array}{l}\begin{array}{l}\text { Professores e alunos em } \\
\text { geral }\end{array} \\
\end{array}$ \\
\hline
\end{tabular}

Fonte: Dados da Pesquisa (2015). 
Iniciou-se também um movimento de aproximação dos três programas de extensão da UNACSA, como forma de potencializar as ações extensionistas, maximizando os alcances.

Em 2013, por meio do Edital no 21/2013, a UNACSA abriu inscrições para o processo de seleção de projetos que tivessem inserção na realidade social, com intuito de estimular e garantir o envolvimento acadêmico na discussão e encaminhamentos das demandas da comunidade. $\mathrm{O}$ período compreendido para execução dos projetos foi de março de 2014 a fevereiro de 2016.

Em março de 2014, por meio do Edital no 5/2014, a UNACSA tornou público o resultado do processo de seleção dos projetos de extensão. Os selecionados foram:

\section{a) Pelo PAES (Programa de Ações em Economia Solidária):}

1. Ações para empreendimentos de economia solidária - rumo a uma incubadora. Esse projeto foi selecionado para participar do Programa de Extensão Território Paulo Freire, com o objetivo de auxiliar no planejamento, na implantação e na condução de empreendimentos sociais existentes ou novos por meio da incubação em incubadora universitária de economia solidária. Teve como orientador o Professor Joelcy José Sá Lanzarini. O total de pessoas beneficiadas, em 20147, foi de 560 . Como resultados alcançados, houve o atendimento de seis grupos de inclusão produtiva nas áreas de artesanato e de produção de alimentos, além do apoio à criação da cooperativa de artesãs.

2. Ações para o fortalecimento da feira de economia solidária da Unesc. Esse projeto teve como objetivo fortalecer a Feira de Economia

\footnotetext{
${ }^{7}$ Os projetos apontam a quantidade de pessoas diretamente beneficiadas, mas se infere que o número se torna maior quando considerados também os beneficiados indiretamente, como, por exemplo, no projeto "Assistência Judiciária", na medida em que os pedidos são enviados à Vara de Execução Penal de Criciúma, beneficiam também os familiares dos presos, fato que dificulta a quantificação. No mesmo contexto, encontra-se o projeto "Mulheres e Cidadania”.
} 
Solidária da Unesc (FES-Unesc) e garantir a sua continuidade periódica por meio do aumento da participação de feirantes e da variedade de produtos. Teve como orientador o Professor Dimas de Oliveira Estevam. O total de pessoas beneficiadas, em 2014, foi 2.746 participantes, entre visitantes e consumidores.

\section{b) Pelo PEDIC (Programa de Extensão em Direito e Cidadania):}

1. Curso de formação em agente comunitária de cidadania. Esse projeto foi selecionado para participar do Programa Território Paulo Freire, com o objetivo de capacitar moradores do Bairro Vila Manaus em curso de formação de agentes comunitários de cidadania, a partir de noções básicas de direito de família e cooperativismo, direitos do consumidor e contratos, direito penal e direitos humanos, direito do trabalho e previdenciário e direito sanitário e constitucional. Teve como orientadora a Professora Sheila Martignago Saleh. O total de pessoas beneficiadas, em 2014, foi de 560 participantes.

2. Saúde pública e participação popular: construindo a cidadania em saúde. Esse projeto foi selecionado para participar do Território Paulo Freire, com o objetivo de desenvolver, implantar e avaliar estratégias para sensibilização dos conselheiros populares de saúde dos Bairros Santa Luzia e São Defende, do município de Criciúma, sobre papéis, funções e formas de atuação, com a finalidade de promover a cidadania. Teve como orientador o Professor Reginaldo de Souza Vieira. As pessoas beneficiadas, em 2014, foram 308 participantes.

3. Projeto solidariedade, cujo objetivo foi desenvolver estratégias que contribuíssem para sensibilizar estudantes das três primeiras fases do curso de Direito da Unesc sobre as realidades dos públicos atendidos por instituições sociais públicas e filantrópicas de Criciúma e municípios vizinhos, com a finalidade de promover a cidadania dos envol- 
vidos. Teve como orientadora a Professora Janete Triches. O total de pessoas beneficiadas, em 2014, foi 5.012 .

4. Assistência judiciária para os(as) reeducandos(as) dos estabelecimentos prisionais de Criciúma, SC, com o objetivo de prestar atendimento judiciário e psicossocial aos(às) reeducandos(as) dos estabelecimentos prisionais de Criciúma, SC, que não possuem advogado, elaborando pedidos para a concessão de benefícios da Execução Penal, tais como remição, indulto, livramento condicional, progressão de regime, liberação de pecúlio, dentre outros, bem como auxiliar na organização de pastas e arquivos dos reeducandos e encaminhar ao Juízo da Vara de Execuções Penais, em atendimento à linha de extensão $n^{\circ} 47$, prevista no item 5.1.1 do Edital no 21/2013 UNACSA. Teve como orientador o Professor Alfredo Engelmann Filho. As pessoas beneficiadas, em 2014, totalizaram 129 participações.

5. Prevenção e erradicação da alienação parental: o direito da criança e do adolescente à convivência familiar sadia. O objetivo desse projeto foi promover o conhecimento e a conscientização acerca da Síndrome da Alienação Parental e difundir os instrumentos jurídicos da Lei da Alienação Parental (Lei no 12.318, de 26 de agosto de 2010) para os genitores assistidos pela Casa da Cidadania do Distrito de Rio Maina, do município de Criciúma, SC, que pretendem desfazer o vínculo conjugal, visando à convivência familiar saudável aos seus filhos. Teve como orientadora a Professora Sheila Martignago Saleh. As pessoas beneficiadas, em 2014, totalizaram 485 participações.

6. Adolescência e cidadania: construindo e socializando conhecimentos sobre a violência de gênero e os direitos das crianças e adolescentes, com jovens do Ensino Médio em Criciúma, SC. Esse projeto teve como objetivo trabalhar os tipos de violência da atualidade, como violência doméstica e familiar (incluindo as diferenças de gênero), escolar (bullying) e web (sites de relacionamento, etc.), bem como difundir os instrumentos jurídicos da Lei Maria da Penha (Lei no 11.340/06) 
e do ECA (Estatuto da Criança e do Adolescente) para adolescentes (15 a 17 anos) que frequentam o Ensino Médio de escolas públicas do município de Criciúma, SC, promovendo o processo de desnaturalização da violência de gênero. Teve como orientador o Professor Ismael Francisco de Souza. As pessoas beneficiadas, em 2014, totalizaram 480 participações.

7. Mulheres e cidadania: costurando conhecimentos sobre a Lei Maria da Penha (Lei no 11.340/2006). O objetivo desse projeto foi difundir os instrumentos jurídicos da Lei Maria da Penha (Lei $\left.\mathrm{n}^{\circ} 11.340 / 06\right)$ e de Direitos Humanos para as mulheres beneficiárias do Programa Bolsa Família, assistidas pelos CRAS de Criciúma, SC, a fim de promover a prevenção da violência doméstica e familiar. Teve como orientadora a Professora Monica Ovinski de Camargo. As pessoas beneficiadas, em 2014, totalizaram 866 participações.

\section{c) Pelo POPE (Programa de Orientação ao Pequeno Empreendedor):}

1. Finanças pessoais para escolas municipais do Território Paulo Freire. Esse projeto foi selecionado para participar do Território Paulo Freire, com o objetivo de permitir que os estudantes, das escolas públicas (municipais) do Território Paulo Freire, pudessem compreender, elaborar e planejar as finanças pessoais. Teve como orientadora a Professora Jucélia da Silva Abel. As pessoas beneficiadas, em 2014, totalizaram 565 participações.

2. Assessoria na gestão, capacitação empresarial e empreendedorismo para empresas incubadas da Itec.in - Incubadora Tecnológica de Ideias e Negócios do IPARQUE (Parque Científico e Tecnológico da Unesc). O objetivo desse projeto foi promover ações de assessoria na gestão, capacitação empresarial e de empreendedorismo para as empresas incubadas na Itec.in (Incubadora Tecnológica de Ideias e Negócios da Unesc), contribuindo para a criação e o desenvolvimento de empresas 
que oferecessem produtos ou serviços tecnologicamente inovadores. Teve como orientador o Professor Ricardo Pieri. Os beneficiados, em 2014, totalizaram 20 empreendimentos.

3. Ações direcionadas à capacitação em empreendedorismo, plano de negócios e responsabilidade social, com o objetivo de desenvolver atividades de extensão universitária, estimulando jovens e adolescentes do Bairro da Juventude na geração de trabalho e renda, com inclusão social, por meio de capacitação empreendedora. Teve como orientador o Professor Abel Correa de Souza. As pessoas beneficiadas, em 2014, totalizaram 74 participações.

Em 2015, a UNACSA lançou o e-book da série "Práticas e Saberes de Extensão, volume I", sob a organização dos professores Daniel Ribeiro Preve, Ismael Francisco de Souza e Milla Lúcia Ferreira Guimarães. Essa obra foi fruto de trabalho coletivo, cujo resultado apresenta relatos de experiências extensionistas, visando não somente ao reconhecimento acadêmico, mas principalmente à socialização dos saberes. A obra é composta por 12 relatos de experiências de extensão, sob forma de artigos, que tratam de temas relativos à economia solidária, empreendedorismo, direito e cidadania. Contempla trabalhos de pesquisadores externos à Unesc e de professores e estudantes dos cursos que compõem a UNACSA, tais como Administração, Administração e Comércio Exterior, Ciências Contábeis, Ciências Econômicas, Secretariado Executivo e Tecnológicos.

A coleção "Práticas e Saberes em Extensão" visa a incentivar e a difundir a produção acadêmica em extensão.

\section{CONSIDERAÇÕES FINAIS}

A extensão, enquanto um dos pilares componentes do tripé da educação, vem ganhando importância cada dia maior dentro da univer- 
sidade. Com a abertura de editais internos para seleção de projetos de extensão da UNACSA, observa-se um aumento do número de professores e de acadêmicos que se envolvem em atividades nessa área. Assim, é fundamental buscar a ampliação do número de projetos para os próximos editais.

Outro ponto importante é o processo de formação que vem sendo implementado pela Unidade Acadêmica ao corpo de extensionistas. Isso tem possibilitado um melhor desempenho em relação aos resultados dos projetos de extensão. Observa-se que os professores e os acadêmicos bolsistas internalizaram os ensinamentos dos cursos de formação e, com isso, a tendência é que os projetos ganhem, a cada dia, qualidade e diversidade.

Nesse movimento, cabe salientar que, no início do ano de 2016, um novo programa de extensão foi aprovado pela Pró-Reitoria de PósGraduação, Pesquisa e Extensão para integrar a UNACSA. O Programa de Extensão em Gestão Contábil é oriundo de um trabalho de conclusão de curso de uma acadêmica de Ciências Contábeis.

Por meio dos projetos de extensão, é possível levar a ciência produzida na universidade à sociedade, auxiliando-a na resolução dos problemas do cotidiano e permitindo a melhoria da qualidade de vida das populações atendidas.

\section{REFERÊNCIAS}

BRASIL. Lei $\mathrm{n}^{\circ} 5.540$, de 28 de novembro de 1968. Fixa normas de organização e funcionamento do ensino superior e sua articulação com a escola média, e dá outras providências. Diário Oficial [da] República Federativa do Brasil. Brasília, DF, 23 de novembro de 1968, retificado em 03 de dezembro de 1968.

FÓRUM DE PRÓ-REITORES DE EXTENSÃO DAS INSTITUIÇÕES PÚBLICAS DE EDUCAÇÃO SUPERIOR BRASILEIRAS - FORPROEX. 
I Encontro de Pró-Reitores de Extensão das Universidades Públicas Brasileiras: Conceito de extensão, institucionalização e financiamento. Brasília: Forproex, 1987, p. 11-18. Disponível em: <https://www.ufmg.br/ proex/renex/images/documentos/1987-I-Encontro-Nacional-do-FORPROEX.pdf>. Acesso em: 10 jun. 2012.

FREIRE, P. Educação como prática de liberdade. 16. ed. São Paulo: Paz e Terra, 1974.

LIMA, M. C. P. B. Modelo matemático para mensurar ações de extensão. Revista Interfaces, Belo Horizonte, v. 2, n. 2, p. 36-53, jan./jun. 2014. Disponível em: <file://C:/Users/Usuario/Downloads/104-283-1-PB.pdf>. Acesso em: 20 jun. 2015.

NOGUEIRA, M. D. P. (Org.). Políticas de extensão universitária brasileira. Belo Horizonte: UFMG, 2005.

PREVE, D. R.; SOUZA, I. F. de; GUIMARÃES, M. L. F. A extensão na universidade comunitária: um olhar a partir da política nacional de extensão universitária. In: PREVE, D. R.; SOUZA, I. F. de; GUIMARÃES, M. L. F. (Orgs.). Práticas e Saberes de Extensão. Vol. II [Recurso eletrônico]. Curitiba: Multideia, 2015, p. 9-25. Disponível em: <https:// www.academia.edu/28181193/PR\%C3\%81TICAS_E_SABERES_DE_ EXTENS\%C3\%83O_Volume_II>. Acesso em: 05 set. 2016.

SANTOS, M. P. Contributos da extensão universitária brasileira à formação acadêmica docente e discente no século XXI: um debate necessário. Revista Conexão UEPG, Ponta Grossa, v. 6, n. 1, p. 10-15, 2012. Disponível em: <http://177.101.17.124/index.php/conexao/article/view/3731/2622>. Acesso em: 20 jun. 2015.

UNIVERSIDADE DO EXTREMO SUL CATARINENSE - UNESC. Resolução no 12/2015/CONSU. Aprova políticas de extensão da Unesc. Criciúma: UNESC, 2015. Disponível em: <http://www.unesc.net/portal/ resources/files/262/Resolu\%C3\%A7\%C3\%A3o\%2012-2015-CONSU\%20 
INSERÇÃO CURRICULAR DA EXTENSÃO:

aproximações teóricas e experiências

VOLUME VI

-\%20Pol\%C3\%ADticas\%20Extens\%C3\%A3o.pdf>. Acesso em: 20 set. 2015. 